\title{
Freeze-Drying versus Heat-Drying: Effect on Protein-Based Superabsorbent Material
}

\author{
Estefanía Álvarez-Castillo (D), Carlos Bengoechea (D), Manuel Felix *(D) and Antonio Guerrero (D) \\ Departamento de Ingeniería Química, Escuela Politécnica Superior, C/Virgen de África, 7, Universidad de Sevilla, \\ 41011 Sevilla, Spain; malvarez43@us.es (E.Á.-C.); cbengoechea@us.es (C.B.); aguerrero@us.es (A.G.) \\ * Correspondence: mfelix@us.es; Tel.: +34-954-557-179
}

check for updates

Citation: Álvarez-Castillo, E.;

Bengoechea, C.; Felix, M.; Guerrero, A.

Freeze-Drying versus Heat-Drying:

Effect on Protein-Based

Superabsorbent Material. Processes

2021, 9, 1076. https://doi.org/

$10.3390 /$ pr9061076

Academic Editor: Petra Först

Received: 2 May 2021

Accepted: 18 June 2021

Published: 21 June 2021

Publisher's Note: MDPI stays neutral with regard to jurisdictional claims in published maps and institutional affiliations.

Copyright: (c) 2021 by the authors. Licensee MDPI, Basel, Switzerland. This article is an open access article distributed under the terms and conditions of the Creative Commons Attribution (CC BY) license (https:// creativecommons.org/licenses/by/ $4.0 /)$.

\begin{abstract}
Porcine plasma protein is a by-product of the meat industry, which has already been applied in the manufacture of superabsorbent materials. The effects of plasticizer content $(0 \%, 25 \%$, $50 \%$ ), together with those of the drying method (freeze-drying, thermal drying at $50{ }^{\circ} \mathrm{C}$ ), during the processing of superabsorbent porcine plasma matrices were studied in this manuscript. Although the presence of glycerol accelerated the water absorption kinetics, the highest water absorption ( $550 \%)$ was achieved by samples not containing any plasticizer. Viscoelasticity decreased at higher glycerol contents and especially after water absorption. When swollen samples were dried through freezedrying, porous structures with a sponge-like appearance were obtained. Oppositely, thermally dried samples suffered an evident shrinkage that reduced porosity, displaying a more uniform surface. The effect of the drying method was observed since only freeze-dried samples can be rehydrated, displaying a superabsorbent ability (absorption higher than $1000 \%$ ), which could be used in several applications (food, agriculture, personal care).
\end{abstract}

Keywords: porcine plasma protein; rheology; polymer processing; superabsorbent materials

\section{Introduction}

Absorbent and superabsorbent materials (SAMs) are able to absorb and retain a huge amount of water (over $1000 \mathrm{wt} . \%$ its own weight) [1]. During and after water absorption, the hydrophilic three-dimensional network can retain a large amount of water without dissolving in it, due to the existence of chemical and physical interactions that keep the structure together [2]. Although these materials have many applications, mainly in the personal care market, most of them are based on non-biodegradable synthetic polymers (i.e., acrylic based) [3]. Growing environmental awareness promotes the replacement of these petrochemical polymers by biodegradable natural polymers [4], whose processing onto biodegradable superabsorbent materials would also bring about a reduction in oil dependence [5].

Proteins are biopolymers comprising different combinations of 20 amino acid residues existing in nature linked by peptide bonds [6]. Moreover, several food industry wastes and by-products are rich in protein fractions, converting them into a relatively cheap, sustainable raw material source for a circular economy [7]. Proteins from different natural sources, such as soy, rapeseed, blood meal, and gluten, among others, have been used for the manufacture of protein-based superabsorbent materials [8-12]. In this sense, the success in the development of superabsorbent materials from protein sources relies on their content of polar amino acids (e.g., aspartic and glutamic acids). Porcine plasma protein, which is a by-product from the meat industry, is rich in hydrophilic residues, and it has already been employed in the food industry as a water-holding agent [13] or has even replaced other raw materials, such as egg [14]. Furthermore, when formulated and processed conveniently, porcine plasma protein can produce biodegradable superabsorbent materials $[11,15,16]$.

The processing method for superabsorbent materials may vary, including extrusion, injection molding, compression molding, and casting [17-20]. These processing techniques 
traditionally used for synthetic polymers typically require a heating stage to promote the formation of the polymer network. Consequently, the reinforcement of the biopolymer network is achieved through the development of covalent bonds, which in counterpart would result in a reduction in the probe swelling and consequently a diminished water absorption capacity [21,22]. The processing conditions of protein-based superabsorbent materials predetermine their further functional properties (i.e., water absorption capacity, stiffness, transparency), and as a result, they can be adjusted to enhance some specific properties [22]. In this context, emerging technologies for polymer processing (e.g., freezedrying) may play a key role in the next polymer generation [23].

Freeze-drying processing allows solvent evaporation without promoting significant structural changes, which, in this kind of materials, would mean maintaining the porous structure formed after water absorption [24]. This would lead to the formation of a spongelike structure in the final freeze-dried matrix, which would be able to reabsorb the solvent. Previous studies have demonstrated that a porous structure has a positive effect on water uptake capacity, facilitating water penetration through the porous structure [11].

Contrary to conventional heat-based processing techniques, the final volume of samples does not change significantly when they are dried by freeze-drying, and if the polymer concentration is high enough to bear its own weight, the tridimensional structure present in the solution remains after solvent evaporation [25]. This processing technique has already been described for the formation of scaffolds for tissue engineering generated from dissolved polymers [26]. However, this method has not been still proposed for the formation of a tridimensional matrix with superabsorbent capacity.

The goal of this work was to analyze the effect of freeze-drying processing compared to natural convection heat-based drying processing to produce protein-based superabsorbent matrices with a sponge-like structure. Porcine plasma protein was initially mixed with glycerol as a plasticizer at three protein/plasticizer ratios (50/50,75/25, and 100/0). Swollen matrices were generated after water immersion for $48 \mathrm{~h}$, and then natural convection heat-based drying and freeze-drying were applied to obtain sponge-like structures with superabsorbent properties. The mechanical properties of the probes at different stages of the process were determined by dynamic mechanical analysis (DMA), whereas the kinetics of water absorption and subsequent reabsorption was also analyzed.

\section{Materials and Methods}

\subsection{Materials}

Proanda Ltd. (Seville, Spain) kindly supplied the porcine plasma protein (PPP; Essentia Proteins, Ankeny, IA, USA) used in this study. According to the results previously reported, the protein content of the PPP system was ca 74\% [11]. Glycerol (Gly) from Panreac Química S.A. (Barcelona, Spain) was the only plasticizer used for all samples. Deionized-grade water was used for water absorption tests.

\subsection{Methods}

Protein-based samples were obtained following a two-stage process: Initially, PPP and glycerol blends were obtained at three different ratios (50/50, 75/25, and 100/0) by using a two-blade counter-rotating Haake Polylab QC batch mixer (ThermoHaake, Karlsruhe, Germany). Blends were obtained at room temperature and $50 \mathrm{rpm}$ for $5 \mathrm{~min}$; subsequently, protein-based samples were obtained after the processing of blends by the Minijet Piston Injection Molding System (ThermoHaake, Karlsruhe, Germany). Cylindrical specimens (10 mm diameter, $15 \mathrm{~mm}$ length) were obtained at $60^{\circ} \mathrm{C}$ and 500 bar pressure for $150 \mathrm{~s}$ [17]. Superabsorbent matrices were generated after submitting protein-based samples to $48 \mathrm{~h}$ of water immersion and subsequent drying either in a conventional oven or by freezedrying. On the one hand, the samples were placed in a UN55 oven (Memmert, Germany) at $50{ }^{\circ} \mathrm{C}$ for $24 \mathrm{~h}$. Samples were subjected to heat-drying under natural convection conditions (in the absence of any forced air circulation). On the other hand, the samples were first conveniently frozen at $-40{ }^{\circ} \mathrm{C}$ for $24 \mathrm{~h}$ in a static freezer (Model EVF 110/45; 
Equitec, Madrid, Spain), and then they were freeze-dried in vacuum flasks fitted to an 8-port manifold of a LyoQuest freeze-dryer (Telstar Technologies, Barcelona, Spain) (condenser temperature: $-85^{\circ} \mathrm{C}$; temperature of sample holder: room temperature; pressure: 0.01 mbar).

\subsubsection{Linear Viscoelastic Properties}

The viscoelastic properties of the samples studied were determined through dynamic mechanical analysis (DMA) within the linear viscoelastic region (LVR). Samples studied included (i) probes after injection molding, (ii) swelled probes after water immersion for $48 \mathrm{~h}$ (i.e., containing the water absorbed), and (iii) superabsorbent matrices obtained either after natural convection thermal drying or after freeze-drying. DMA tests consisted of frequency tests (from 0.01 to $20 \mathrm{~Hz}$ ) performed in an RSA-III rheometer (TA Instruments, New Castle, DE, USA) at room temperature. A 10-mm-diameter cylindrical compression geometry was selected for these tests. Prior to frequency tests, strain sweep tests were performed to select a strain within the LVR.

\subsubsection{Water Uptake and Swelling Ratio}

The water uptake capacity (WUC) and the soluble matter loss (SML) were determined after placing the samples (1-1.5 g) in a vessel containing $300 \mathrm{~mL}$ of water. These parameters were estimated for the injection-molded probes and superabsorbent matrices as follows [27]:

$$
\begin{aligned}
& \operatorname{WUC}(\%)=\frac{\mathrm{w}_{\mathrm{t}}-\mathrm{w}_{0}}{\mathrm{w}_{0}} \cdot 100 \\
& \operatorname{SML}(\%)=\frac{\mathrm{w}_{0}-\mathrm{w}_{\mathrm{d}}}{\mathrm{w}_{0}} \cdot 100
\end{aligned}
$$

where $\mathrm{w}_{0}$ refers to the initial weight of the sample, $\mathrm{w}_{\mathrm{t}}$ to the weight of the sample after water immersion for a time $t$ (swollen samples), and $w_{d}$ to the weight of dried samples after water immersion.

To analyze the effect of protein content on absorption properties, the WUC can also be referred to the initial protein content as follows:

$$
\mathrm{WUC}_{p}(\%)=\frac{\mathrm{w}_{\mathrm{t}}-\mathrm{w}_{0} \cdot x_{p}}{\mathrm{w}_{0} \cdot x_{p}} \cdot 100
$$

where $x_{p}$ is the protein fraction present $(0.5,0.75$, and 1 for $50 / 50,75 / 20$, and $100 / 0$ PPI/Gly ratios, respectively).

Apart from the WUC and SML, the kinetics of the water absorption was also estimated by measuring the increase in weight as a function of time. No external load was applied during the water uptake measurements.

During water immersion, the dimensions of the samples (diameter and height) were measured to determine their volume, as well as the swelling kinetics observed, along with the immersion time. The swelling ratio (S) was calculated as follows:

$$
\mathrm{S}(\%)=\frac{\mathrm{v}_{t}-\mathrm{v}_{0}}{\mathrm{v}_{0}} \cdot 100
$$

where $\mathrm{v}_{0}$ refers to the initial volume (immersion time: $0 \mathrm{~h}$ ) and $\mathrm{v}_{t}$ refers to the volume of the sample after immersion time $t$.

The water absorption kinetics was fitted to a pseudo-first-order model, expressed as

$$
\ln \left(W U C_{e q}(\%)-W U C_{t}(\%)\right)=\ln W U C_{e q}(\%)-k t
$$

where $\mathrm{WUC}_{\mathrm{eq}}$ and $\mathrm{WUC}_{\mathrm{t}}$ are the water uptake values (\%) at the maximum value and at a given time $\mathrm{t}(\mathrm{h})$, respectively, and $\mathrm{k}$ is the absorption kinetic constant. 
The parameter $\Psi$ was defined to compare the WUC and $S$ results as a function of immersion time:

$$
\Psi=x_{p}\left(\frac{W U C+1}{S+1}\right)=x_{p}\left(\frac{\rho_{t}}{\rho_{0}}\right)
$$

where $\rho_{0}$ and $\rho_{t}$ are the densities of the protein matrix before and after water immersion, respectively, for a given time, $t$.

\subsubsection{Scanning Electron Microscopy}

The surface of superabsorbent matrices obtained after thermal drying or freeze-drying was analyzed by scanning electron microscopy (SEM) using a ZEISS EVO instrument (Oberkochen, Germany). Samples were Au/Pt-coated (12 nm) in a Leica AC600 instrument (Wetzlar, Germany). The working distance was $6 \mathrm{~mm}$, whereas an acceleration voltage of $10 \mathrm{kV}$ and a beam current of $11 \mathrm{pA}$ were used for these measurements.

\subsection{Statistical Analysis}

The results included in this work were the average value of at least three samples. Statgraphics 18 software (Statgraphics Technologies, Inc., The Plains, VA, USA) was used to perform one-way ANOVA tests $(p<0.05)$. Standard deviations were included for all the parameters determined, whereas significant differences were indicated by different letters.

\section{Results and Discussion}

\subsection{Generation of Absorbent Matrices}

\subsubsection{Water Absorption Properties}

Figure 1 shows the water uptake kinetics for compression-molded porcine plasma protein (PPP)-based materials plasticized with Gly in different PPP/Gly ratios: 50/50, $75 / 25$, and 100/0. This graph evidenced a clear dependence of the WUC and absorption kinetics on the PPP/Gly ratio. Thus, the system containing the highest amount of Gly (PPP/Gly ratio: 50/50) also exhibited the fastest water absorption kinetics, since it reached a maximum value (ca. $260 \%$ ) after $48 \mathrm{~h}$ of immersion and then remained virtually constant for longer immersion times. A slower kinetics was observed for systems with 75/25 and 100/0 PPP/Gly ratios as the maximum WUC values were achieved at the longest time studied within the experimental time frame. Other authors [11] have reported the positive effect of Gly on protein-based superabsorbent materials since its hydrophilic character facilitates the penetration of water through the porous protein network formed as glycerol is released into the immersion medium. The formation of these pores associated with the release of Gly facilitates the faster absorption observed in Figure 1 when Gly is present in the formulation as compared to the non-plasticized system (100/0). It may be noted that this non-plasticized system displays WUC values higher than that containing Gly, and the higher WUC finally achieved corresponds to the 100/0 system. These higher WUC values can be attributed to the higher protein content of these samples, as PPP is a hydrophilic protein. Thus, the WUC at the original protein content $\left(W U C_{p}\right)$ was estimated as $641 \% \pm 38 \%$ and $459 \% \pm 10 \%$ for $50 / 50$ and $100 / 0$ ratios after $48 \mathrm{~h}$ water absorption, respectively. These results expressed as water uptake at the original protein content were higher than the ones found for potato-protein-based absorbent materials [28]. Moreover, a higher $\mathrm{WUC}_{\mathrm{p}}$ was detected at a lower initial PPP content. This is understandable as the presence of glycerol leads to the formation of a higher number of pores within the immersed sample, which can enhance absorption by the protein matrix. Differences between WUC and $W_{\mathrm{U}}$ highlight the role of the plasticizer in the swelling process. $\mathrm{WUC}_{\mathrm{p}}$ results neglect the solubilization of a certain protein fraction that actually takes place during immersion, as pointed out by the SML values observed. The SML values obtained after $48 \mathrm{~h}$ for the $50 / 50,75 / 25$, and $100 / 0$ systems were $52.5 \% \pm 1.2 \%, 35.3 \% \pm 2.28 \%$, and $13.3 \%$ $\pm 2.6 \%$, respectively. Thus, samples with higher Gly content also exhibited higher SML values, since the SML has been essentially associated with the release of Gly during water immersion, due to its high hydrophilic character [29]. Thus, the amount of mass lost to the 
immersion medium is directly dependent on the quantity of plasticizer used. Moreover, in addition to glycerol, some protein was also transferred into the immersion medium. In fact, PPP was solubilized to a higher extent as the protein content originally present in the sample was higher (i.e., $2.5 \%, 10.3 \%$, and $13.3 \%$ protein was estimated to be lost for the $50 / 50,75 / 25$, and 100/0 systems, respectively). WUC values were higher than those obtained by soy-based absorbent materials [22] but similar or slightly lower than those obtained by porcine plasma [17], both processed by injection molding.
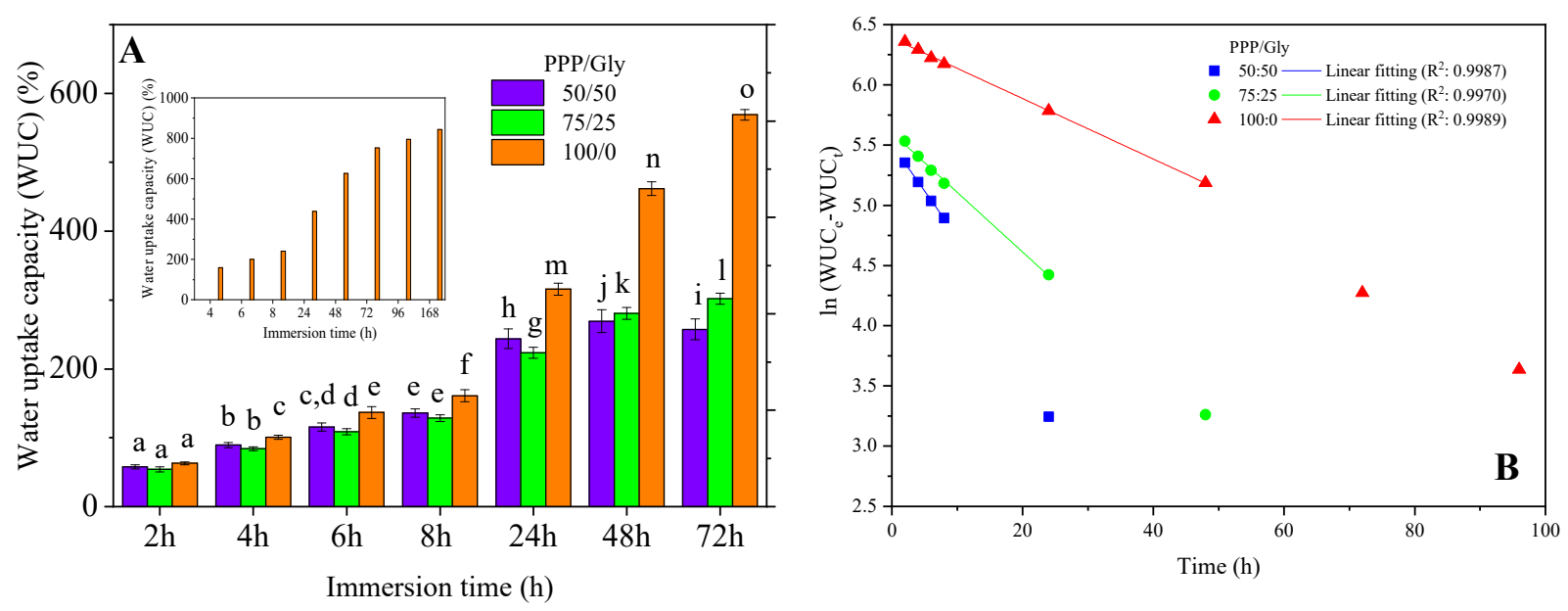

Figure 1. (A) Water uptake kinetics and (B) pseudo-first-order kinetic model for compression-molded porcine plasma protein (PPP)-based materials plasticized with glycerol (Gly) with different PPP/Gly ratios: 50/50, 75/25, and 100/0. Inset in Figure 1A shows the evolution of the 100/0 system over $168 \mathrm{~h}$ adsorption time.

The water absorption kinetics is shown in Figure 1B. Thus, the water absorption process follows a first-order absorption kinetics. The $\mathrm{k}$ values of $50 / 50,75 / 25$, and $100 / 0$ systems were $0.076,0.034$, and 0.026 , respectively. Note that the experimental data followed the linear fitting only when the WUC had an exponential increase. The highest water absorption rate obtained for the $50 / 50$ system at room temperature can be associated with the higher amount of Gly extracted that would generate larger pore sizes in the biopolymer matrix.

Table 1 shows the swelling (S) kinetics of the samples with immersion time. A general increase in $\mathrm{S}$ was noted at longer immersion times for all samples showing a tendency to reach a plateau, independently of the PPP/Gly ratio used. That increase was quite similar for all samples up to $8 \mathrm{~h}$ of immersion. From that time on, a higher increase was indirectly related to the glycerol content, the sample with a PPP/Gly ratio of 100/0 being the one that reached the highest value of $S$ at $48 \mathrm{~h}$ (around 530\%). The $\Psi$ parameter compares the WUC and $\mathrm{S}$ results as a function of immersion time. Thus, from the definition of parameters WUC and S (Equations (1) and (2)), it can be inferred that parameter $\Psi$ is a function of the relative density. As can be deduced from Table 1, the protein fraction times the relative density of the matrix (i.e., parameter $\Psi$ ) remains close to unity after immersion for $8 \mathrm{~h}$ for the three systems studied. These results indicate that a period of immersion of $8 \mathrm{~h}$ or longer is required to achieve a balance between the increase in volume due to swelling and the increase in mass due to water absorption. 
Table 1. Swelling kinetics for compression-molded porcine plasma protein (PPP)-based materials plasticized with glycerol (Gly) with different PPP/Gly ratios: 50/50, 75/25, and 100/0. Significant letters within a column indicates significant differences $(p<0.05)$.

\begin{tabular}{|c|c|c|c|c|c|c|}
\hline \multirow[b]{2}{*}{ Immersion Time (h) } & \multicolumn{3}{|c|}{ Swelling Ratio (\%) } & \multicolumn{3}{|c|}{ Parameter $\Psi$} \\
\hline & System $50 / 50$ & System $75 / 25$ & System 100/0 & System $50 / 50$ & System $75 / 25$ & System $100 / 0$ \\
\hline 2 & $81.32^{\mathrm{a}}$ & $72.49^{a}$ & $131.72^{\mathrm{a}}$ & 1.43 & 1.63 & 0.77 \\
\hline 4 & $89.82^{\mathrm{a}}$ & $126.36^{b}$ & $181.19^{b}$ & 1.66 & 1.24 & 0.82 \\
\hline 6 & $202.64^{c, d}$ & $190.59^{c, d}$ & $236.37^{c}$ & 0.88 & 0.98 & 0.81 \\
\hline 8 & $208.98^{d}$ & $194.81^{\mathrm{c}, \mathrm{d}}$ & $236.37^{e}$ & 0.95 & 1.09 & 0.94 \\
\hline 24 & $316.04^{\mathrm{f}}$ & $335.87^{f}$ & $398.60^{g}$ & 0.99 & 0.99 & 1.04 \\
\hline 48 & $327.41^{f}$ & $385.72 \mathrm{~g}$ & $532.82^{\mathrm{h}}$ & 1.04 & 1.05 & 1.11 \\
\hline
\end{tabular}

A comparison between the WUC values from Figure $1 \mathrm{~A}$ and the $\mathrm{S}$ values from Table 1 reveals that they are quite similar for the non-plasticized system (e.g., after immersion for $24 \mathrm{~h}$, the WUC and S values for the 100/0 system were ca. $410 \%$ and $400 \%$, respectively). However, the two Gly-containing matrices showed higher values for the former parameter, which is particularly perceptible for samples with a higher plasticizer content (e.g., after immersion for $24 \mathrm{~h}$, the WUC and S values for the 50/50 system were ca. $630 \%$ and $320 \%$, respectively, whereas the 75/25 system yielded values of $440 \%$ and $340 \%$, respectively). This effect is due to the formation of pores within the polymeric structure as the glycerol is extracted and transferred to the immersion bath. As a result, water absorption in these two systems is not solely due to swelling of the protein matrix but also to the diffusion through the pores formed over glycerol extraction.

It can also be noted that the two Gly-containing matrices showed parameter $\Psi$ values higher than unity after immersion for 2 and $4 \mathrm{~h}$. These results suggest that this time is not enough to fully remove Gly, giving rise to WUC values higher than expected and still moderate protein swelling. In contrast, the Gly-free system displayed values moderately lower than unity below an immersion time of $8 \mathrm{~h}$. It seems that the increase in mass due to the incorporation of water into the matrix is lower than the increase in volume produced by swelling. This event is progressively attenuated as water absorption grows, eventually leading to the above-mentioned balance achieved after an immersion time longer than 8-10 h. Some slight increase in the $\Psi$ value after a long immersion time may be indicative of some protein loss by solubilization.

\subsubsection{Viscoelastic Properties}

Figure 2A shows the frequency sweep tests obtained for compression-molded PPPbased materials plasticized with Gly at three different PPP/Gly ratios, 50/50, 75/25, and $100 / 0$, before water immersion. The mechanical spectra obtained for these systems evidenced a predominant solid behavior, since the elastic modulus was higher than the viscous modulus regardless of the Gly content within the entire range of frequency studied. However, the results indicate that the microstructure of the systems obtained strongly depends on the Gly content, leading to a remarkable reduction in the viscoelastic properties as PPP is replaced by Gly in the formulation [30,31]. The system without Gly (PPP/Gly ratio: 100/0) showed nearly parallel viscoelastic moduli, where the response obtained was not significantly dependent on frequency. However, the dependence on frequency increased as the Gly content increased, especially at low frequency values, suggesting protein chain mobility when the relaxation time was high enough [32]. This is especially apparent for the system containing the greatest amount of plasticizer (PPP/Gly ratio: 50/50), with a more important frequency dependence of the viscoelastic moduli, as well as lower values. Moreover, E' and E" got closer as Gly content increased. Thus, this is a clear plasticizing effect of Gly, since plasticizers decrease protein-protein hydrogen bond interactions, leading to an increase in free volume and molecular mobility [21,33]. Therefore, the increase in protein mobility found as the Gly content increased was a consequence of conformational changes, which, in turn, affected the final properties of 
the bioplastics observed [34]. An analogous dependence of the mechanical response on the plasticizer content has already been reported for protein-based bioplastics, determining the final techno-functional properties [35]. Apart from the changes in the shape of the mechanical spectra, the increase in the amount of plasticizer also involved a decrease in the viscoelastic moduli, since $\mathrm{E}^{\prime}$ at $1 \mathrm{~Hz}$ decreased from $(1.14 \pm 0.04) \times 10^{8}$ Pa for the sample with a PPP/Gly ratio of $100 / 0$ to $(4.71 \pm 0.03) \times 10^{7} \mathrm{~Pa}$ and $(7.35 \pm 0.06) \times 10^{6} \mathrm{~Pa}$ for the samples with PPP/Gly ratios of 75/25 and 50/50 PPI/Gly, respectively. This decrease in the elastic moduli as a consequence of plasticizer increase has also been observed in other protein-based materials, being attributed not only to an increase in protein mobility, caused by the relaxation of the interactions between polymeric chains, but also to a decrease in protein content $[11,36]$. Moreover, these values are similar to the ones obtained for other protein-based bioplastics $[15,29,37]$.

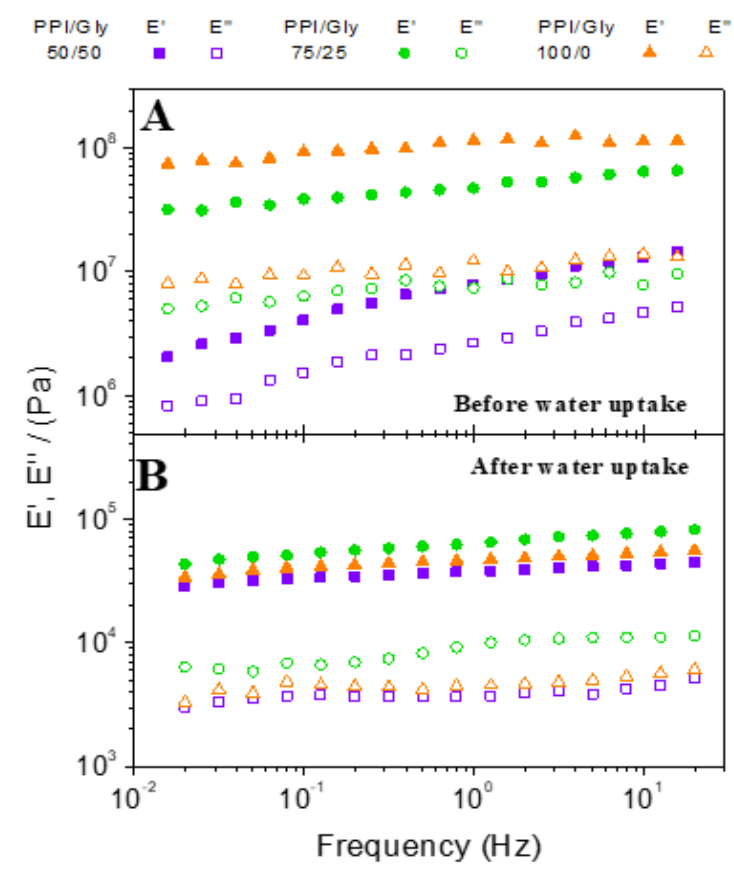

Figure 2. Frequency sweep tests for compression-molded porcine plasma protein (PPP)-based materials plasticized with glycerol (Gly) with different PPP/Gly ratios, 50/50, 75/25, and 100/0, (A) before immersion and (B) swelled after immersion.

Figure 2B shows the mechanical spectra obtained for the swollen probes after $48 \mathrm{~h}$ of water immersion. According to the mechanical spectra obtained, all swollen PPP-based probes showed a different microstructure from that of the original sample before immersion. The entrapment of water in the polymeric matrix during water immersion resulted in all samples displaying qualitatively similar mechanical spectra, independent of the formulation. The mechanical spectra of swollen samples displayed a lower dependency on frequency, especially for samples originally processed with glycerol. It is worth mentioning that according to the results shown above, no glycerol remained inside any of the protein matrices studied after water immersion for $24 \mathrm{~h}$. Quantitatively, a drastic drop of 3 orders of magnitude in the viscoelastic moduli took place when compared to the original samples (from $\sim 100 \mathrm{MPa}$ to $\sim 60 \mathrm{kPa}$ ). This effect has also been observed in other absorbent materials $[38,39]$. In this sense, water exerts a remarkable plasticizing effect in protein systems, reducing protein-protein interactions and eventually decreasing viscoelastic properties [40]. When comparing swollen samples, it can be noted that differences between samples were much smaller than before immersion. The lowest values for the elastic moduli at $1 \mathrm{~Hz}$ were observed for the system with the PPP/Gly ratio of 50/50 (37,500 $\pm 84 \mathrm{~Pa})$, whereas the highest values were observed for the system with the PPP/Gly ratio of 75/25 $(63,280 \pm 69 \mathrm{~Pa})$. The system without a plasticizer displayed an intermediate behav- 
ior $(46,500 \pm 53 \mathrm{~Pa})$. These results evidence that the microstructure of the swollen systems depends to a higher extent on the final water uptake value, which is higher for the 50/50 PPP/Gly ratio and, therefore, cannot be directly related to the initial Gly content.

\subsubsection{Microstructural Characterization}

Swollen samples with different PPP/Gly ratios (50/50, 75/25, and 100/0) were dried through two different procedures (heat processing using a natural convection oven and freeze-drying at low temperature and pressure). Then, the microstructure of the samples was analyzed through scanning electron microscopy (SEM). The differences found between the microstructure of the freeze-dried and heat dried samples are shown in Figure 3.
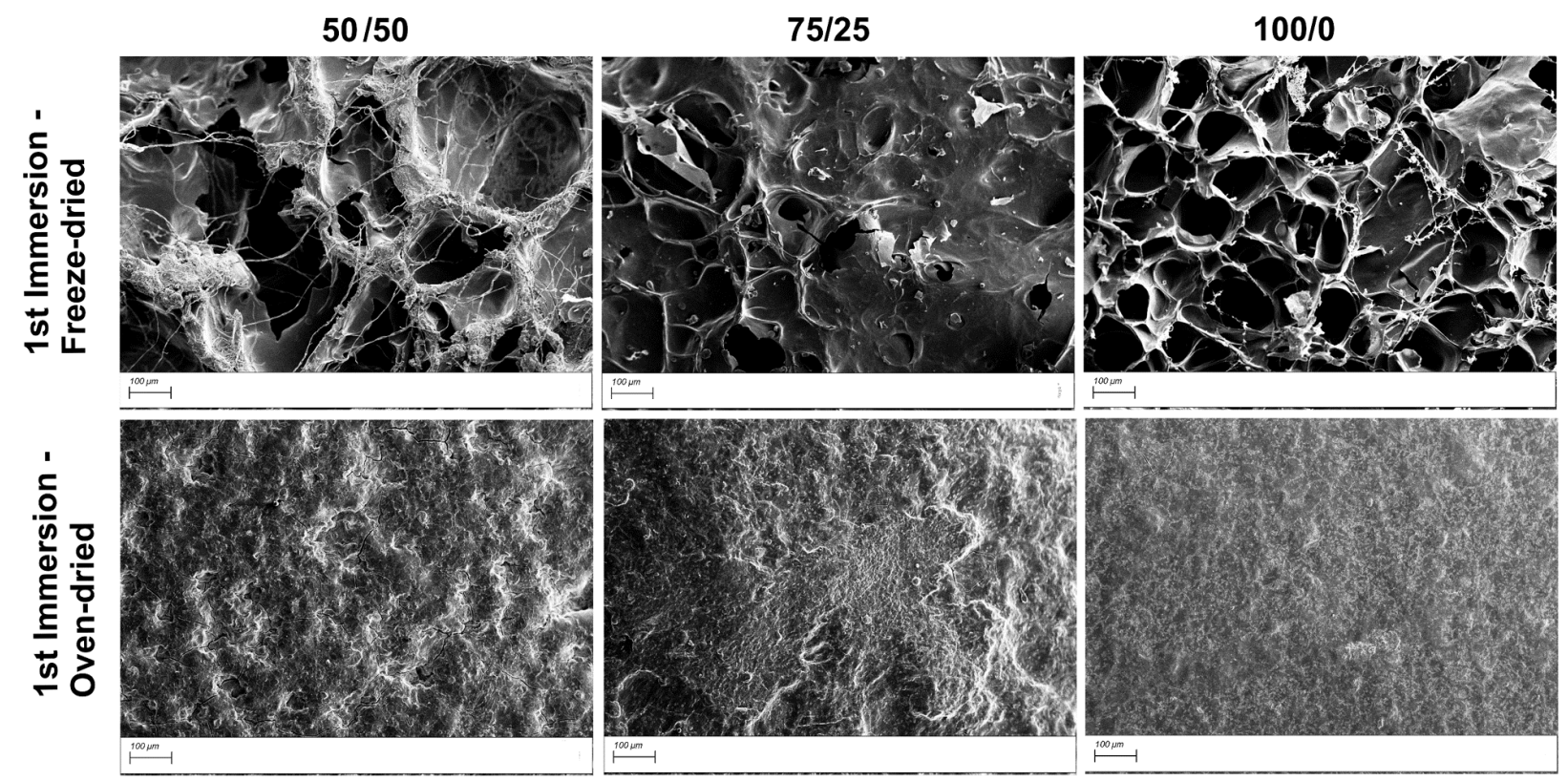

Figure 3. Scanning electron microscopy (SEM) images of compression-molded porcine plasma protein (PPP)-based materials plasticized with glycerol (Gly) with different PPP/Gly ratios, 50/50, 75/25/, 100/0, after the first water immersion and the drying stage (freeze-drying or thermal drying).

Heat-dried samples displayed a rougher surface for higher glycerol contents. The drying of samples in the oven at $50^{\circ} \mathrm{C}$ produced a uniform structure that lacked the porosity observed in the freeze-dried samples. Even if glycerol has been reported to induce the formation of pores in protein samples, the sample without glycerol $(100 / 0)$ showed a more homogeneous porous structure, with smaller pore sizes than the larger pores displayed by samples with 50/50 and 75/25 PPP/Gly ratios. The larger pore size of the 50/50 system, which is associated with the extraction of Gly, would explain the faster kinetics observed (Figure 1). An estimation of the specific surface area from SEM images indicated that it ranged from 35,000 to $70,400 \mathrm{~mm}^{-1}$ for the freeze-dried probes, whereas it ranged from 140 to $180 \mathrm{~mm}^{-1}$ for the thermal dried samples. However, these values would only explain the initial water absorption kinetics, since the dimensions of the pores and the sizes of the probes varied during water uptake.

Figure 4 shows the visual appearance of the PPP-based materials with different PPP/Gly ratios at different stages of their processing: (i) just after compression molding, (ii) after water immersion, and (iii) after freeze-drying or (iv) after heat-drying in the oven (natural convection). It is apparent that all the studied samples suffered a noteworthy increase in volume after water immersion, as denoted in the above-commented swelling ratio. It can be noted that the sample with a PPP/Gly ratio of 75/25 was the one with lower water retention. Moreover, the freeze-drying procedure did not lead to a perceptible change in volume when comparing swollen and freeze-dried samples, while the sample dried in a natural convection oven showed an apparent shrinkage. Thus, the drying procedure 
defined the eventual structure of samples, as freeze-drying and heat-drying produced completely different samples in which differences in porosity were clear.

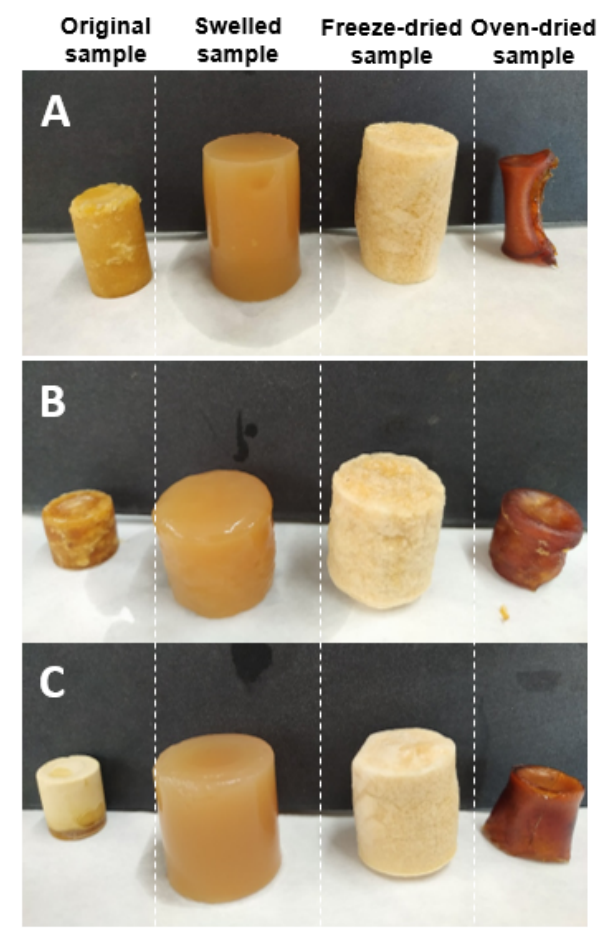

Figure 4. Appearance of swollen, freeze-dried, and heat-dried (in a natural convection oven) compression-molded porcine plasma protein (PPP)-based materials with different PPP/Gly ratios: 50/50 (A), 75/25 (B), and 100/0 (C).

\subsection{Superabsorbent Matrices: Effect of the Drying Method \\ 3.2.1. Water Absorption Properties}

The different microstructures obtained through each drying procedure also influence the reabsorption kinetics of the matrices once they have been dried. Figure 5 shows the water uptake kinetics for dried porcine plasma protein (PPP)-based matrices initially plasticized with Gly at different PPP/Gly ratios (50/50 (A), 75/25 (B), and 100/0 (C)) after being dried either by freeze-drying or by thermal drying in a natural convection oven. Results obtained indicated faster kinetics for the absorbent matrices obtained through freeze-drying, since they reached their maximum values sooner than those obtained by heat-drying in a natural convection oven. This can be a consequence of the sponge-like structure obtained when matrices were processed through freeze-drying, which facilitated water intrusion within the polymeric structure.

Moreover, the freeze-dried matrices also exhibited a higher WUC than those obtained after drying at $50{ }^{\circ} \mathrm{C}$ in a natural convection oven, regardless of the PPP/Gly ratio used $(50 / 50,75 / 25$, and 100/0). This may be explained by the uniform structure, lacking pores, shown by heat-dried samples (Figure 3), which is the result of the heat-induced shrinking suffered by their microstructure. For all the systems studied, the maximum water uptake capacity was obtained after $6 \mathrm{~h}$ water immersion, since no higher values with significant differences were obtained for longer times. Unlike freeze-dried matrices, the systems obtained by heat-drying in a natural convection oven only reached an apparent steady value after $8 \mathrm{~h}$ water immersion for the 50/50 PPP/Gly ratio. The other two heat-dried systems (i.e., PPP/Gly ratios: 75/25 and 100/0) still did not reach a plateau value after $24 \mathrm{~h}$ water immersion. This may be related to the different mechanism for pore formation when different drying procedures were used, as freeze-dried samples presented a sponge-like appearance, which evidenced greater porosity. The interconnection of the observed pores promoted water absorption, with faster absorption kinetics. In contrast, the heat-dried 
samples showed a closed structure that required longer immersion times to be entirely hydrated. Longer times were not analyzed, as they are not recommended for common service conditions of superabsorbent materials. Nevertheless, the results obtained indicate that there are no important differences in the WUC when the matrices are processed by freeze-drying at different PPP/Gly ratios. There was a slight decrease when the PPP/Gly ratio increased (from $1757 \% \pm 225 \%$ to $1217 \% \pm 520 \%$ for $100 / 0$ and $50 / 50$ PPP/Gly ratios, respectively). In any case, these values were significantly higher than the highest value obtained by heat-drying in a natural convection oven $(\sim 1370 \%$ for the $100 / 0$ ratio after $24 \mathrm{~h}$ water immersion). Moreover, the WUC values displayed by the different samples were always higher during the second immersion, once they had been previously swollen and dried. During the second immersion, the WUC was higher for the swollen systems dried by freeze-drying, indicating that this strategy is successful for the development of superabsorbent materials. The protein-based superabsorbent materials obtained exhibited higher or similar absorbent capacity than other materials processed by injection molding, such as soy, pea, and porcine plasma $[11,37,41]$, being similar to the results obtained by porcine plasma at $\mathrm{pH} 3$ [15] or soy protein after acylation [27].
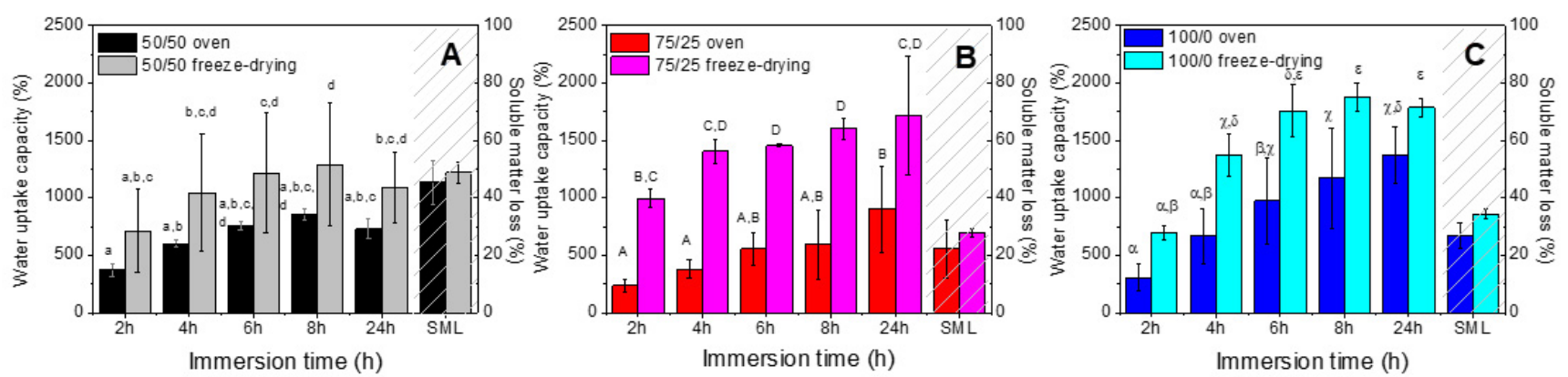

Figure 5. Water uptake kinetics for dried porcine plasma protein (PPP)-based matrices initially plasticized with glycerol (Gly) with different PPP/Gly ratios, 50/50 (A), 75/25 (B), and 100/0 (C), after drying either by freeze-drying or by heat-drying in a natural convection oven.

\subsubsection{Viscoelastic Properties}

Figure 6A shows the frequency sweep tests of samples dried in a natural convection oven at $50{ }^{\circ} \mathrm{C}$. The mechanical spectra obtained are typical of a solid-like structure since $\mathrm{E}^{\prime}$ is above the $\mathrm{E}^{\prime \prime}$ for the whole frequency range studied, and both moduli show a slight dependence on frequency. Moreover, there were no significant differences between the $\mathrm{PPP} / \mathrm{Gly}$ ratios of $100 / 0$ and $50 / 50(13.78 \pm 0.05 \mathrm{MPa})$, while higher values were obtained for the system at the 75/25 PPP/Gly ratio $(23.02 \pm 0.09 \mathrm{MPa})$. These higher values observed for the 75/25 sample agree with the lower water retention displayed in Figure 1. Although the mechanical spectra obtained evidenced an elastic behavior in the same way as the probes before immersion (Figure 2A), the values obtained were around 1 order of magnitude lower, indicating the formation of softer matrices after water absorption and further drying in a natural convection oven.

Figure 6B shows the frequency sweep tests of PPP-based superabsorbent materials plasticized with Gly at different PPP/Gly ratios, 50/50, 75/25, and 100/0, dried by freeze-drying. Contrary to probes dried in a natural convection oven, which possessed a shrunken appearance, these probes showed a much more porous, sponge-like structure (Figures 3 and 4). This different visual appearance was reflected in the mechanical spectra obtained for these systems, since they exhibited higher viscoelastic moduli (i.e., $\mathrm{E}^{\prime}$ at $1 \mathrm{~Hz}$ for the 75/25 PPP/Gly ratio was $\sim 9 \mathrm{MPa}$ instead of $\sim 23 \mathrm{M} \mathrm{Pa}$ ). Moreover, the increase in the solid character observed for the probes thermally dried in a natural convection oven was also reflected in the value of $\tan \delta\left(\tan \delta=E^{\prime \prime} / E^{\prime}\right)$, since it decreased from 0.08 to $0.07(\sim 12.5 \%)$. These differences highlighted the importance of the drying procedure used on the microstructure and, consequently, on the viscoelastic properties. 

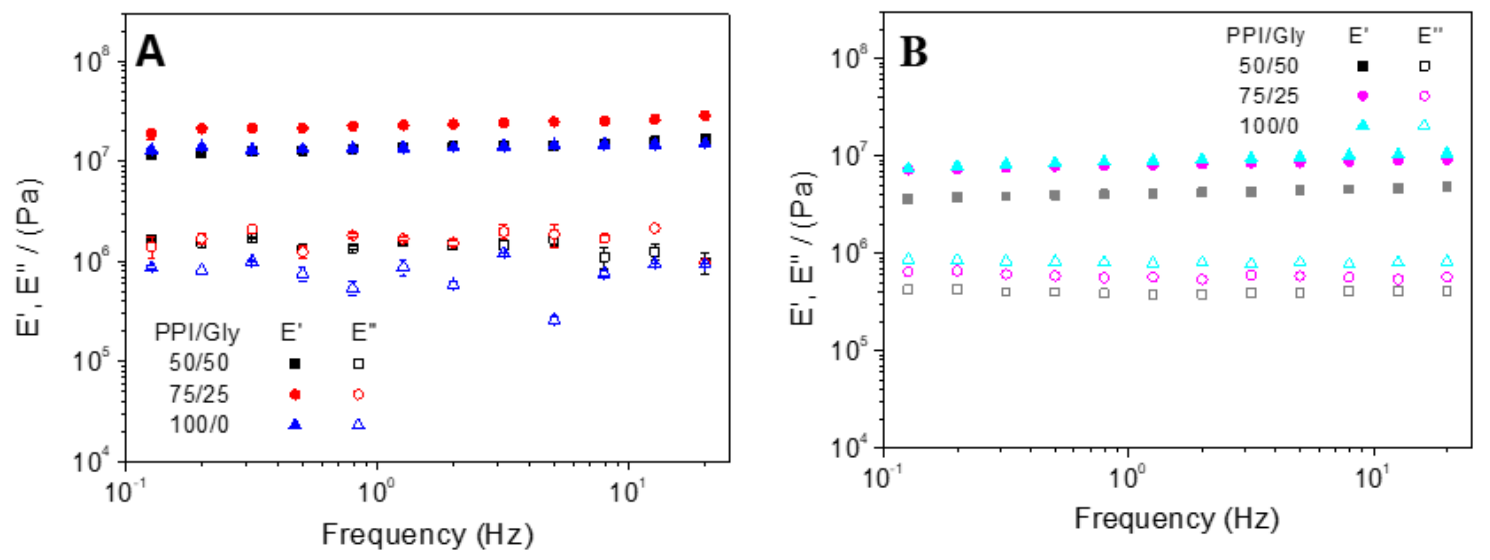

Figure 6. Frequency sweep tests for porcine plasma protein (PPP)-based materials plasticized with glycerol (Gly) with different PPP/Gly ratios, 50/50, 75/25, and 100/0, dried after swelling with two different methods: (A) natural convection oven at $50{ }^{\circ} \mathrm{C}$ and (B) freeze-drying.

\subsubsection{Microstructural Characterization}

Figure 7 shows the microstructure of dried samples after reabsorption. This figure evidences an increase in porosity when compared to the same samples after the first immersion (Figure 3), which can be only compared with the PPP/Gly ratio of 100/0. Heatdried samples displayed a porous structure after reabsorption, indicating the regeneration of the porous structure after heat-drying. However, the structure of the heat-dried matrix was more continuous and with more irregular pores than the polyhedral pores detected for freeze-dried samples, which can be related to the slower water absorption kinetics observed for these samples.
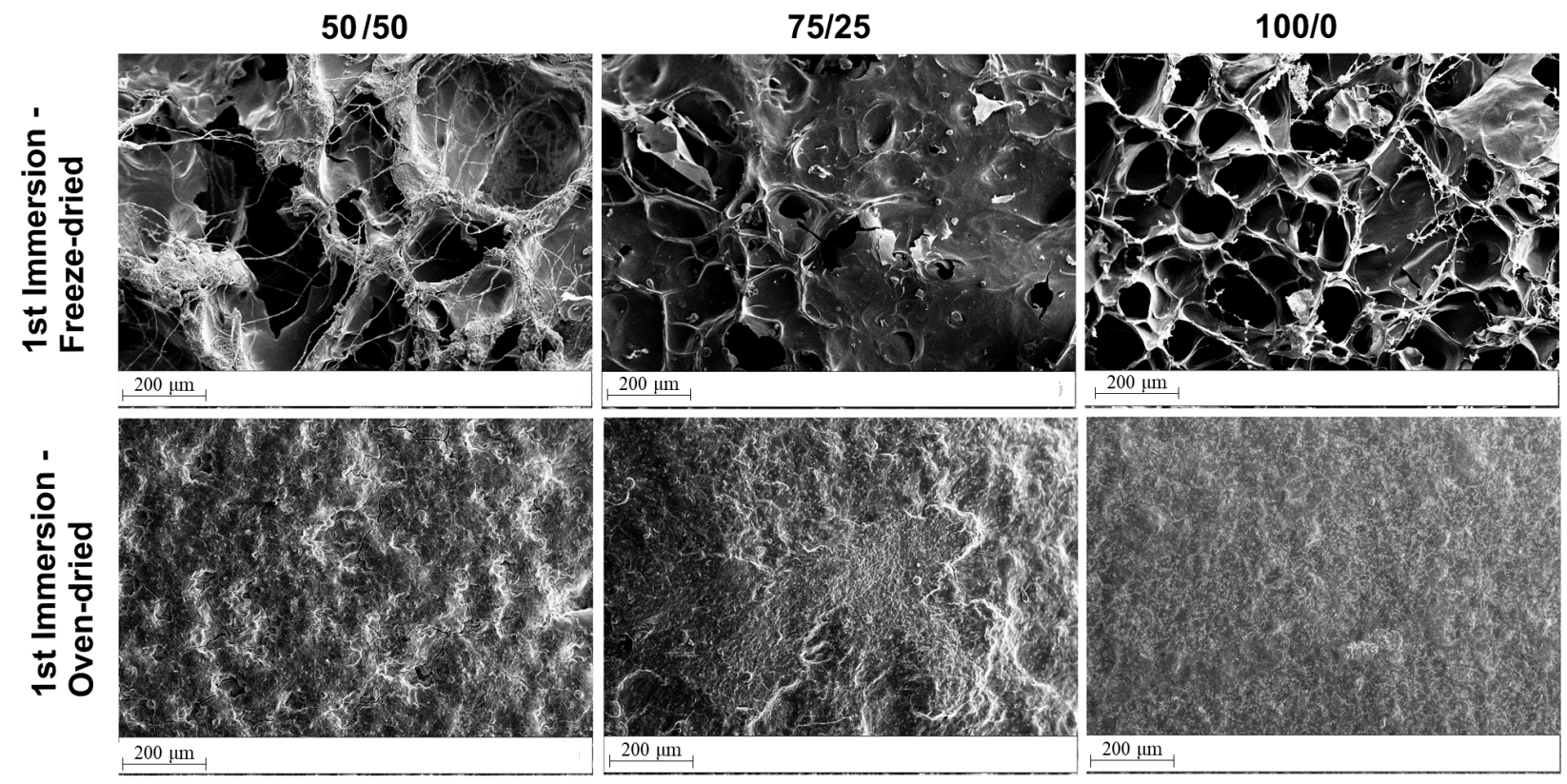

Figure 7. Scanning electron microscopy (SEM) images of compression-molded porcine plasma protein (PPP)-based materials plasticized with glycerol (Gly) with different PPP/Gly ratios, 50/50, 75/25, and 100/0, after the first water immersion, the drying stage (freeze-drying or thermal drying), the second water immersion, and the final freeze-drying.

These images confirm the effect of the drying method on the microstructure of the samples and, consequently, on the absorption properties of protein-based adsorbent and superabsorbent materials. The freeze-drying process involves the formation of a more porous microstructure, which facilitates solvent penetration, and in turn, it leads to higher 
absorption kinetics and capacity. In other words, a different drying process after the first immersion eventually yields remarkable differences in the microstructure of the final porous matrix.

\section{Conclusions}

This work demonstrates the effect of the drying method on the absorbent properties of PPP-based materials, where the sample composition also plays a key role. A higher glycerol content in compression-molded porcine plasma materials accelerates the water absorption during water immersion through pseudo-first-order kinetics. However, higher absorption values are shown by samples with a higher protein content, which is explained by the high hydrophilicity of porcine plasma protein.

The microstructure of the swollen probes is determined by the amount of water absorbed and the drying procedure followed afterward. When freeze-dried, the samples show a porous structure, with larger pore sizes at high glycerol contents. However, when heat-dried, the structure closes and packs more tightly, resulting in an apparent shrinkage. These microstructural modifications, depending on the formulation and drying method selected for the processing of samples, are reflected in the rheological behavior of the probes. Thus, the samples dried after water immersion are more packed than those obtained just after compression molding, which results in higher viscoelastic moduli and a lower loss tangent.

During rehydration, samples obtained after freeze-drying behaved as superabsorbent materials that typically absorbed more water as immersion times were longer, which can be successfully used in some applications (e.g., food, agriculture, personal care). Thus, the freeze-drying process involves the formation of a highly porous microstructure, which facilitates solvent penetration and, in turn, leads to higher absorption kinetics and capacity. This result evidences the importance of the processing method on the microstructure of the material generated, where the freeze-drying process leads to superabsorbent matrices with specific applications.

Author Contributions: Conceptualization, E.Á.-C., M.F., C.B., and A.G.; validation, C.B. and A.G.; formal analysis, E.Á.-C. and M.F.; investigation, E.Á.-C. and M.F.; resources, C.B. and A.G.; data curation, E.Á.-C. and M.F.; writing-original draft preparation, E.Á.-C. and M.F.; writing-review and editing, C.B. and A.G.; supervision, M.F., C.B., and A.G.; project administration, C.B. and A.G.; funding acquisition, C.B. and A.G. All authors have read and agreed to the published version of the manuscript.

Funding: This study was financially supported by the FEDER/Ministerio de Ciencia e InnovaciónAgencia Estatal de Investigación, through the project RTI2018-097100-B-C21 and through the PhD grant PRE2019-089815.

Institutional Review Board Statement: Not applicable.

Informed Consent Statement: Not applicable.

Data Availability Statement: All the results shown in the manuscript can be requested from the corresponding author.

Acknowledgments: The authors would like to thank the Spanish Ministerio de Ciencia e Innovación (MCI)/Agencia Estatal de Investigación (AEI)/Fondo Europeo de Desarrollo Regional (FEDER, UE) for the financial support provided through the funding of the RTI2018-097100-BC21 (MCI/AEI/FEDER, UE) project. The authors also acknowledge the Spanish Ministerio de Universidades for the PhD grant PRE2019-089815 awarded to E. Álvarez-Castillo. Furthermore, the authors also thank the Universidad de Sevilla for hiring M. Felix (call II.5, VPPI US).

Conflicts of Interest: All the authors confirm that the manuscript has not been previously published, being an original work. The authors also declare that they have no known competing financial interests or personal relationships that could have appeared to influence the work reported in this paper. 


\section{References}

1. Álvarez-Castillo, E.; Bengoechea, C.; Guerrero, A. Effect of $\mathrm{pH}$ on the properties of porcine plasma-based superabsorbent materials. Polym. Test. 2020, 85, 106453. [CrossRef]

2. Álvarez-Castillo, E.; Bengoechea, C.; Guerrero, A. Composites from by-products of the food industry for the development of superabsorbent biomaterials. Food Bioprod. Process. 2020, 119, 296-305. [CrossRef]

3. Álvarez-Castillo, E.; Bengoechea, C.; Rodríguez, N.; Guerrero, A. Development of green superabsorbent materials from a by-product of the meat industry. J. Clean. Prod. 2019, 223, 651-661. [CrossRef]

4. Álvarez-Castillo, E.; Del Toro, A.; Aguilar, J.M.; Guerrero, A.; Bengoechea, C. Optimization of a thermal process for the production of superabsorbent materials based on a soy protein isolate. Ind. Crop. Prod. 2018, 125, 573-581. [CrossRef]

5. Álvarez-Castillo, E.; Pelagio, M.J.; Bengoechea, C.; Guerrero, A. Plasma based superabsorbent materials modulated through chemical cross-linking. J. Environ. Chem. Eng. 2021, 9, 105017. [CrossRef]

6. Athamneh, A.I.; Griffin, M.; Whaley, M.; Barone, J.R. Conformational Changes and Molecular Mobility in Plasticized Proteins. Biomacromolecules 2008, 9, 3181-3187. [CrossRef]

7. Avérous, L. Biodegradable Multiphase Systems Based on Plasticized Starch: A Review. J. Macromol. Sci. Part C 2004, 44, 231-274. [CrossRef]

8. Capezza, A.J.; Glad, D.; Özeren, H.D.; Newson, W.R.; Olsson, R.T.; Johansson, E.; Hedenqvist, M.S. Novel Sustainable Superabsorbents: A One-Pot Method for Functionalization of Side-Stream Potato Proteins. ACS Sustain. Chem. Eng. 2019, 7, 17845-17854. [CrossRef]

9. Capezza, A.J.; Lundman, M.; Olsson, R.T.; Newson, W.R.; Hedenqvist, M.S.; Johansson, E. Carboxylated Wheat Gluten Proteins: A Green Solution for Production of Sustainable Superabsorbent Materials. Biomacromolecules 2020, 21, 1709-1719. [CrossRef]

10. Cortes-Trivino, E.; Martinez, I. Wheat gluten/montmorillonite biocomposites: Effect of $\mathrm{pH}$ on the mechanical properties and clay dispersion. Express Polym. Lett. 2018, 12, 616-627. [CrossRef]

11. Cuadri, A.A.; Romero, A.; Bengoechea, C.; Guerrero, A. The Effect of Carboxyl Group Content on Water Uptake Capacity and Tensile Properties of Functionalized Soy Protein-Based Superabsorbent Plastics. J. Polym. Environ. 2018, 26, 2934-2944. [CrossRef]

12. Damodaran, S. Protein Stabilization of Emulsions and Foams. J. Food Sci. 2006, 70, R54-R66. [CrossRef]

13. De'Nève, B.; Shanahan, M. Water absorption by an epoxy resin and its effect on the mechanical properties and infra-red spectra. Polym. 1993, 34, 5099-5105. [CrossRef]

14. Delgado, M.; Felix, M.; Bengoechea, C. Development of bioplastic materials: From rapeseed oil industry by products to added-value biodegradable biocomposite materials. Ind. Crop. Prod. 2018, 125, 401-407. [CrossRef]

15. Dhakal, H.; Zhang, Z.; Richardson, M. Effect of water absorption on the mechanical properties of hemp fibre reinforced unsaturated polyester composites. Compos. Sci. Technol. 2007, 67, 1674-1683. [CrossRef]

16. Emadian, S.M.; Onay, T.T.; Demirel, B. Biodegradation of bioplastics in natural environments. Waste Manag. 2017, 59, 526-536. [CrossRef]

17. Felix, M.; Martín-Alfonso, J.; Romero, A.; Guerrero, A. Development of albumen/soy biobased plastic materials processed by injection molding. J. Food Eng. 2014, 125, 7-16. [CrossRef]

18. Felix, M.; Martinez, I.; Romero, A.; Partal, P.; Guerrero, A. Effect of pH and nanoclay content on the morphology and physicochemical properties of soy protein/montmorillonite nanocomposite obtained by extrusion. Compos. Part B Eng. 2018, 140, 197-203. [CrossRef]

19. Felix, M.; Romero, A.; Cordobes, F.; Guerrero, A. Development of crayfish bio-based plastic materials processed by small-scale injection moulding. J. Sci. Food Agric. 2014, 95, 679-687. [CrossRef]

20. Félix, M.; Romero, A.; Martín-Alfonso, J.; Guerrero, A. Development of crayfish protein-PCL biocomposite material processed by injection moulding. Compos. Part B Eng. 2015, 78, 291-297. [CrossRef]

21. Fernández-Espada, L.; Bengoechea, C.; Cordobés, F.; Guerrero, A. Protein/glycerol blends and injection-molded bioplastic matrices: Soybean versus egg albumen. J. Appl. Polym. Sci. 2016, 133, 42980. [CrossRef]

22. Fernández-Espada, L.; Bengoechea, C.; Sandía, J.A.; Cordobés, F.; Guerrero, A. Development of novel soy-protein-based superabsorbent matrixes through the addition of salts. J. Appl. Polym. Sci. 2019, 136, 47012. [CrossRef]

23. Ferry, J.D. Viscoelastic Properties of Polymers; Wiley: Hoboken, NJ, USA, 1980.

24. Grenier, J.; Duval, H.; Barou, F.; Lv, P.; David, B.; Letourneur, D. Mechanisms of pore formation in hydrogel scaffolds textured by freeze-drying. Acta Biomater. 2019, 94, 195-203. [CrossRef]

25. Hurtado, S.; Dagà, I.; Espigulé, E.; Parés, D.; Saguer, E.; Toldrà, M.; Carretero, C. Use of porcine blood plasma in "phosphate-free frankfurters". Procedia Food Sci. 2011, 1, 477-482. [CrossRef]

26. Jobling, A. An introduction to rheology H.A. Barnes, J.F. Hutton and K. Walters, Elsevier Science Publishers, Amsterdam, 1989. pp. v + 199, Price \$6050/Dfl 115.00. ISBN 0-444-87469-0. Polym. Int. 1991, 25, 61. [CrossRef]

27. Laohakunjit, N.; Noomhorm, A. Effect of Plasticizers on Mechanical and Barrier Properties of Rice Starch Film. Starch-Stärke 2004, 56, 348-356. [CrossRef]

28. Lu, G.; Chen, T. Application of egg white and plasma powders as muscle food binding agents. J. Food Eng. 1999, 42, 147-151. [CrossRef]

29. Mann, G.S.; Singh, L.P.; Kumar, P.; Singh, S. Green composites: A review of processing technologies and recent applications. J. Thermoplast. Compos. Mater. 2018, 33, 1145-1171. [CrossRef] 
30. Matak, K.E.; Tahergorabi, R.; Jaczynski, J. A review: Protein isolates recovered by isoelectric solubilization/precipitation processing from muscle food by-products as a component of nutraceutical foods. Food Res. Int. 2015, 77, 697-703. [CrossRef]

31. Mezger, T.G. The Rheology Handbook. In The Rheology Handbook; Walter de Gruyter GmbH: Berlin, Germany, 2019.

32. Perez-Puyana, V.; Felix, M.; Romero, A.; Guerrero, A. Influence of the processing variables on the microstructure and properties of gelatin-based scaffolds by freeze-drying. J. Appl. Polym. Sci. 2019, 136, 47671. [CrossRef]

33. Perez-Puyana, V.; Felix, M.; Romero, A.; Guerrero, A. Effect of the injection moulding processing conditions on the development of pea protein-based bioplastics. J. Appl. Polym. Sci. 2016, 133, 43306. [CrossRef]

34. Sachlos, E.; Czernuszka, J.T. Making Tissue Engineering Scaffolds Work. Review: The application of solid freeform fabrication technology to the production of tissue engineering scaffolds. Eur. Cells Mater. 2003, 5, 29-40. [CrossRef] [PubMed]

35. Shi, W.; Dumont, M.-J.; Ly, E.B. Synthesis and properties of canola protein-based superabsorbent hydrogels. Eur. Polym. J. 2014, 54, 172-180. [CrossRef]

36. Ullah, F.; Othman, M.B.H.; Javed, F.; Ahmad, Z.; Akil, H.M. Classification, processing and application of hydrogels: A review. Mater. Sci. Eng. C 2015, 57, 414-433. [CrossRef] [PubMed]

37. Verbeek, C.J.R.; Berg, L.E.V.D. Development of Proteinous Bioplastics Using Bloodmeal. J. Polym. Environ. 2010, 19, 1-10. [CrossRef]

38. Verbeek, C.J.R.; Berg, L.V.D. Extrusion Processing and Properties of Protein-Based Thermoplastics. Macromol. Mater. Eng. 2010, 295, 10-21. [CrossRef]

39. Zárate-Ramírez, L.S.; Martínez, I.; Romero, A.; Partal, P.; Guerrero, A. Wheat gluten-based materials plasticised with glycerol and water by thermoplastic mixing and thermomoulding. J. Sci. Food Agric. 2010, 91, 625-633. [CrossRef]

40. Zohuriaan-Mehr, M.J.; Kabiri, K. Superabsorbent polymer materials: A review. Iran. Polym. J. Engl. Ed. 2008, 17, 447-451.

41. Zohuriaan-Mehr, M.J.; Omidian, H.; Doroudiani, S.; Kabiri, K. Advances in non-hygienic applications of superabsorbent hydrogel materials. J. Mater. Sci. 2010, 45, 5711-5735. [CrossRef] 